\title{
Metodologias Ativas de Ensino e Aprendizagem no Curso de Direito: Breves Relatos da Experiência na Faculdade Ages
}

\author{
Celso Eduardo Santos De Melo \\ Faculdade de Direito da Universidade de São Paulo \\ * Autor para correspondência: celso-de-melo@usp.br
}

\section{RESUMO}

Este relato tem por finalidade expor uma experiência de utilização de metodologia ativa de ensino e aprendizagem no curso de Direito da Faculdade Ages. A base metodológica empregada pretende incentivar o estudante a buscar elementos para a elaboração de casos para estudo (narrativas com propósitos educativos produzidas a partir da realidade vivenciada pelos alunos), que serão vistos em todos os trabalhos desenvolvidos em sala de aula. O modelo ora apresentado tem como objetivo reunir ensino, pesquisa e extensão em um só modus operandi. Os casos para estudo são elaborados a partir dos relatórios de observação da realidade, obtidos em projetos de extensão. Os professores de cada disciplina proporcionam discussões com "tempestade de ideias" e os alunos levantam hipóteses e formulam questionamentos que serão respondidos de acordo com a pesquisa em doutrina, legislação e jurisprudência adequadas para as hipóteses de solução dos problemas identificados. Como resultado, cada aluno apresenta um texto escrito com sua resposta e elabora um mapa conceitual relacionando os elementos práticos e teóricos que compõem sua solução para o caso indicado. Este exercício de problematização é proposto segundo o Arco de Maguerez com o objetivo de dinamizar as aulas e colocar os alunos como protagonistas de seu próprio ensino e aprendizagem.

Palavras-Chave: Problematização; Ensino; Direito; Metodologia.

\begin{abstract}
This report aims to expose an experience of using active teaching and learning methodology in the Law course of the Faculty Ages. The methodological basis employed intends to encourage the student to seek elements for the elaboration of cases for study (narratives with educational purposes elaborated from the reality lived by the students), that will be used in all the works developed in classrooms. The model presented here aims to bring together teaching, research and extension in a single modus operandi. The case studies are based on the reality observation reports obtained in extension projects. Teachers in each discipline provide a brainstorming and students raise questions and formulate questions that will be answered in line with the research in doctrine, legislation and jurisprudence appropriate to the hypothesis of solving the problems identified. As a result, each student presents a written text with his answer and elaborates a conceptual map relating the practical and theoretical elements that make up his solution for the proposed case. This problem-solving exercise is proposed according to the Maguerez' Arch with the purpose of dynamizing the classes and placing students as protagonists of their own teaching and learning.
\end{abstract}

Keywords: Problematization; Teaching; Law; Methodology.

\section{Introdução}

O presente relato de experiência pretende expor breves considerações a respeito da aplicação de metodologias ativas de ensino e aprendizagem no curso de Direito da Faculdade Ages. A base metodológica desenvolvida proporciona ao estudante a possibilidade de buscar, em dados da realidade, depois de estes terem sido discutidos e analisados conforme um prévio projeto integrador, elementos para a construção de casos de papel, ou seja, de narrativas que trazem um contexto para ser utilizado na vivência de práticas educativas que associam conhecimentos prévios a temáticas dos componentes curriculares (MAMEDE, 2001), 
que serão aproveitados em todos os trabalhos desenvolvidos em salas de aula. Desse modo, os alunos contribuem para sua própria formação, na medida em que compõem as propostas de aula com seus conhecimentos e indagações extraescolares, fortalecendo assim uma aprendizagem significativa (PELIZZARI et al., 2002).

Desde a sua origem, em 2001, essa faculdade privada situada em Paripiranga, uma cidade do Polígono das Secas, no interior baiano, pioneira na sua região, tem desenvolvido como proposta pedagógica a utilização de metodologias ativas de ensino e aprendizagem. Tal diretriz pedagógica é aplicada nessa instituição não apenas no ensino superior, como também no ensino fundamental e médio, já que ela existe há mais de 33 anos. Começou como uma escola de educação infantil até ser reconhecida hoje como centro universitário, passando por muitas abordagens pedagógicas em seu percurso, sempre almejando o melhor ensino para seus pupilos. Nesse passo, por essas metodologias ativas terem sido bem produtivas em outros níveis, o mesmo foi adotado no ensino superior dessa instituição.

No nível superior, a abordagem inicial de metodologias ativas foi feita buscando-se estofo nas práticas de $\mathrm{PBL}$, cujos paradigmas principais (MAMEDE, 2001) foram aqueles aplicados em universidades canadense (McMaster), holandesa (Maastricht) e norte-americana (Harvard). Esse foi o modelo seguido no Brasil por alguns cursos na área da saúde, como os da Faculdade de Medicina de Marília e da Universidade Estadual de Londrina (RIBEIRO, 2008). No entanto, esse modelo demasiado rígido, fixado em sete passos de exploração e aprendizagem, não se mostrou adequado ao perfil de aluno e instituição da Faculdade Ages.

Considerando o perfil de alunos oriundos de uma região com mais de setenta municípios, de diversas origens sociais e culturais, grande parte egressos do ensino público, percebeu-se que tais discentes tinham muitas fragilidades com as tecnologias básicas da linguagem e da matemática, de modo que a autoinstrução não poderia dar-se como firmado naqueles paradigmas do PBL, por limitações estruturais dos próprios estudantes. Seria preciso utilizar métodos ativos, mas com outras possibilidades, mais condizentes com a realidade do alunado dessa região.

Quanto à instituição, com perfil participativo de sua gestão, verificou-se que, por mais que a faculdade oferecesse um suporte pedagógico e construtivo, muitos professores se queixavam da rigidez do modelo $\mathrm{PBL}$, como método definido de aprendizagem em equipes de alunos bem reduzidas, espaço mais amplo extraclasse e dedicação integral do aluno a sua formação. A maior parte de seus alunos estuda no período noturno ou em um sistema de calendário alternativo, com aulas ao longo do dia, de quinta-feira a sábado. São alunos que exercem atividades econômicas, seja como empresários rurais, seja como empregados. No curso de calendário alternativo, há um expressivo número de estudantes que são servidores públicos, que incrementam o corpo discente já mencionado. Por esses motivos, a instituição buscou construir seu modelo próprio de metodologia ativa de ensino e aprendizagem, sobretudo com a experiência da aplicação do PBL em seu curso de Enfermagem. Basicamente, o método adotado posteriormente se arrima no esquema de Maguerez, focando-se no ensino por meio de um roteiro previamente discutido, a ser seguido em instrução, bem como da problematização, conforme as bases teóricas de Bordenave e Pereira (2010). Segundo esses autores, a metodologia de problematização com o arco de Maguerez consiste no estudo e investigação estruturados em um processo de etapas cujos pontos de partida e de chegada são a realidade vivenciada pelo aluno. A etapa inicial é de observação da realidade e definição do problema, quando os alunos com orientação do professor observam uma dada situação e a problematizam. A segunda etapa envolve a definição dos pontos-chave de estudo, por meio de tópicos ou questões. A terceira etapa consiste na teorização, em que se buscam respostas melhor elaboradas ao problema identificado e seus pontos-chave. Essas etapas devem ter como finalidade a transformação 
da realidade observada (ZITSCHER, 1999). A quarta etapa propõe apresentar, de modo criativo e original, hipóteses de solução para os problemas verificados. Com isso, a última etapa retorna à realidade analisada e aplica as soluções sugeridas, observando a relevância de seu aprendizado para contribuir na resolução dos problemas e na busca da transformação da realidade (VARGAS et al., 1996).

A instituição promove semestralmente suas semanas acadêmicas com os professores e coordenadores pedagógicos, sendo momento de discussão das fragilidades do semestre anterior, das novas diretrizes e de elaboração de um planejamento pedagógico. A semana acadêmica é realizada durante o período de recesso dos alunos. Os professores são convocados por seus coordenadores para cumprirem um conjunto de tarefas que vão desde leituras e oficinas, a partir de textos pedagógicos, a atividades mais práticas como visitas e simulações. Relatos e discussão dos planos de atuação durante o semestre servem de material para ajustes. Como recurso à capacitação constante, sempre são convidados especialistas em educação no ensino superior para a apresentação e discussão de temas que colaborem com a proposta metodológica da instituição. No planejamento pedagógico das aulas são definidos os roteiros a serem seguidos nos processos de ensino e aprendizagem de cada aula, sempre orientados pela problematização. Seguem-se os temários de cada disciplina, além de uma síntese de propostas de multidisciplinaridade, interdisciplinaridade, transdisciplinaridade, definidas em um projeto integrador. Trata-se a semana acadêmica justamente como um momento dedicado a definir diretrizes quanto à condução de disciplinas dos cursos, reunindo suas afinidades em habilidades e competências. O currículo dos cursos é desenvolvido dentro dos parâmetros formais, porém com foco na formação por competências e habilidades, de modo que os conteúdos das disciplinas recebem um tratamento participativo tanto dos professores quanto dos alunos.

Definidas as linhas gerais desse projeto integrador das disciplinas dos cursos, são conduzidas as aulas estruturadas, que se desenvolvem com base em dados da realidade e nos casos elaborados a partir dos relatórios de observação feitos por professores de cada disciplina juntamente com os alunos. Fecha-se o ciclo com as avaliações formativas e progressivas, que correspondem a uma sistemática de avaliação que visa à construção de conhecimentos, e não à mera classificação quantitativa das disciplinas cursadas. Esse modelo de metodologia ativa de ensino e aprendizagem tem como objetivos reunir o ensino, a pesquisa e a extensão em um só modus operandi. Desse modo, o aluno não fica apenas em busca do ensino nas salas de aula, mas busca alcance prático do seu conhecimento em medidas extraclasse, com pesquisa e extensão, interagindo com a sociedade e seu cotidiano.

\section{Desenvolvimento}

Mas como essas metodologias ativas têm sido aplicadas no curso de Direito, um curso formal e tradicionalmente muito técnico em suas linguagens jurídicas e diplomas legais? O modelo de ensino jurídico no Brasil e nos países que seguem o sistema jurídico da Civil Law no mundo, ou seja, a estrutura de normas jurídicas e o modo de conhecer e interpretar o direito, cuja fonte principal de normas jurídicas é a lei criada pelo Estado, tem priorizado o estudo exaustivo em perspectiva metodológica dogmática e formal do direito positivo. Quer dizer, partindo-se do pressuposto de que o direito é norma jurídica legal originária do monopólio estatal de formação do direito, deve ser estudado através de seus códigos e diplomas legais. Essas leis em geral são escritas de modo abstrato, autônomo e genérico, por vezes muito distantes da realidade de vários alunos. A principal dinâmica empregada nas aulas se dá por meio da exposição pelo professor que elege os temas e as respectivas doutrinas de seu interesse e formação. Os alunos são meros coadjuvantes nesse processo, passivos ouvintes que apenas participam ou interagem com a permissão dos professores para perguntas ou considerações a respeito do que eles já expuseram. Por vezes, o 
professor vira um porta-voz das doutrinas e livros didáticos dos cursos, reproduzindo os conteúdos da bibliografia sugerida. Esse modelo não prepara os alunos para a atividade jurídica prática, e torna-se muito mais obsoleto ao se ponderar que o estudo do Direito atualmente requer a superação do positivismo tradicional, considerando a argumentação e a ponderação jurídicas necessárias ao mundo normativo dos princípios jurídicos.

Dessa realidade, é muito comum a queixa dos alunos dos cursos jurídicos ante a decepção de ver uma ciência social aplicada se tornar uma ciência de coleção de termos e conteúdos normativos sem aplicação fora dos modelos pensados pelos professores; ou seja, o que se vê em sala não se opera na vida profissional ao deixar as faculdades. Sendo assim, a academia fornece um diploma, mas não a preparação adequada para a vida profissional e social que os alunos pretendem ao buscar a universidade.

No caso do curso de Direito da faculdade, com a aplicação da metodologia ativa desenvolvida pela coordenação pedagógica e aplicada pelos docentes do curso, tem-se conseguido dinamizar as aulas e trazer o aluno para o centro do processo de ensino e aprendizagem. A cada aula são conduzidas discussões com "tempestade de ideias" e levantamento de hipóteses baseadas na formulação de questionamentos. Esses questionamentos serão respondidos de acordo com a pesquisa em doutrina, legislação e jurisprudência adequadas às hipóteses de solução dos problemas identificados. Como resultado, cada aluno apresenta em texto escrito sua resposta, bem como elabora um mapa conceitual estabelecendo relações entre os elementos fáticos e teóricos que compõem sua respectiva solução do caso proposto. Como exemplo, pode ser citado o seguinte caso elaborado por um grupo de alunos do curso de Direito do terceiro semestre, que levou à problematização de um fato muito corriqueiro na região onde os alunos estudam e habitam: a falta de respeito pelos moradores da legislação de trânsito nas vias locais. Esse caso passou a ser utilizado no ensino e aprendizagem das turmas de primeiro semestre:
A caminho da aula de reposição na Faculdade Ages de Tucano, sábado, 9 horas, Mévio fora surpreendido por uma blitz no km 227 da BR 116. O policial rodoviário logo questionou $\mathrm{O}$ estudante de Direito, que costuma estar em dia com toda a documentação, o motivo de estar com farol desligado, já que, fato público e notório, a Lei 13.290/16 alterou o Código de Trânsito Brasileiro (CTB, Lei 9.503/97) para tornar obrigatório o uso de farol aceso em rodovias durante o dia. Tício, colega de turma, logo orientou-o a, em sede de recurso administrativo, usar o argumento de que a população está acostumada a esta prática, motivo este suficiente para revogar a referida Lei. Durante a aula de Introdução ao Estudo do Direito, os colegas levantaram a questão para a turma. Norma, defensora do juspositivismo, manifestou-se a favor da punição em casos como este, tendo em vista que aquilo que está posto deve ser cumprido, além do mais, acrescentou que tal medida legislativa deve ter sido baseada em critérios técnicos e talvez estatísticas de acidentes por conta de farol apagado durante o dia. Maria, contrariamente, defendeu que, segundo entendimento da doutrina, a lei em questão trata a obrigatoriedade apenas para rodovias, o que pode ser questionado, pois com a construção de postos de gasolina, pousadas, bares, e a própria faculdade, o local do fato pode ser considerado um perímetro urbano. Em concordância, Caio dispôs que, caso algum condutor tenha seu veículo multado nas avenidas das cidades, por questão da lei do farol aceso, poderá acionar penal e administrativamente os responsáveis pelo ato, devendo o Estado responder por danos materiais e morais, cumulativamente, a teor da Súmula 37 do STJ. Maria, contestando, afirmou que, caso houvesse essa possibilidade, esta súmula não poderia ter uma aplicação obrigatória, pois não é vinculante (alunos do curso de Direito - $3^{\circ}$ semestre).

Competências a serem desenvolvidas:

- Compreender o conceito de fato jurídico;

- Relacionar as fontes do direito;

- Diferenciar jusnaturalismo e juspositivismo. 
A partir desse caso, os alunos do primeiro semestre discutiram os conhecimentos apresentados em seus componentes curriculares, observando essa realidade descrita, identificando os problemas conforme as demais etapas de destaque de pontos-chave, teorização e hipóteses de solução. Ao final, juntamente com os alunos de outros colegiados, buscaram empregar suas propostas de intervenção, como campanhas de conscientização de condutores de veículos com faixas informativas e eventos em vias públicas, educação para trânsito em escolas, divulgação das leis de trânsito aos infratores, entre outras ações.

Mediante esse exercício de problematização, é possível dinamizar as aulas e retirar os alunos da postura passiva de meros espectadores, para se tornarem protagonistas de seu processo de ensino e aprendizagem.

Essa dinâmica proporciona a formação por competências e habilidades, tornando os alunos aptos a interagirem com os problemas e buscarem soluções. Ele não precisa se debruçar sobre vastos conteúdos e diversos textos sem necessária aplicação, pois, previamente, lhe são apresentadas situações que fazem a busca por informação ser necessária, e a seleção de conteúdos ser mais útil para a realidade que pretende conhecer. Os problemas são geradores de indagação e investigação, por isso devem ser bem significativos aos alunos e à coletividade. Com o projeto integrador, que se desenvolve com um professor tutor e alunos voluntários, são traçadas metas a partir de base de dados escolhidos entre os temas sugeridos pelos professores para desenvolver as disciplinas. Por exemplo, ao estudarem disciplinas correspondentes a direito administrativo, o projeto integrador pode buscar informações em órgãos públicos ou em serviços públicos que são prestados. A investigação prévia é sempre conduzida pelo professor conforme as diretrizes do curso, como definidas na semana acadêmica e no roteiro de instrução. Todos os conteúdos são abordados, mas de modo dinâmico e prático e não meramente mecânico e abstrato, com leitura de doutrinas e códigos.
Considerando os desafios do ensino jurídico no Brasil e sobretudo as carências de formação básica de muitos dos alunos da região, os resultados desse processo de ensino e aprendizagem têm sido muito eficientes, visto que a instituição possui os melhores índices da região da avaliação em seu curso de Direito, tanto pelo MEC quanto pela aprovação em Exames da Ordem, pela OAB.

\section{Conclusão}

Percebe-se que a utilização de metodologias ativas para o curso de Direito nesta faculdade conseguiu atingir maior proveito no ensino e aprendizagem ao mesmo tempo que se busca a interação dos sujeitos com a necessidade de também municiá-los com ferramentas intelectuais para que possam agir de forma autônoma e competente. Assim, essas competências se tornam ainda mais importantes, porque vão capacitar o sujeito na sua busca de adequação e resposta ao ambiente formado por conhecimento, tecnologia e mercado. A necessidade de se selecionarem informações para cada situação é primordial para o objetivo ser alcançado de forma eficiente e assertiva. Essa necessidade é suprida com uma formação zetética jurídica para capacitar a realização dessa inclusão do sujeito nesse mundo pós-moderno (no sentido de vários núcleos interativos e interdependentes, porém descentralizados).

Portanto, somente pensando num aspecto mais amplo de currículo, práticas didáticas e envolvimento dos sujeitos nesses processos, voltados para a resposta aos questionamentos da sociedade, sempre com vistas ao momento histórico de mudanças e transformações que hodiernamente tem lançado constantes desafios na formação dos sujeitos e sua adequação à realidade do trabalho e do mercado, é possível se estabelecer uma proposta adequada de ensino e formação profissional para estudantes de Direito.

\section{Referências Bibliográficas}

BORDENAVE, Juan Díaz \& PEREIRA, Adair Martins. Estratégias de Ensino-Aprendizagem. 30. ed. Petrópolis, RJ: Vozes, 2010. 
MAMEDE, Silvia. "Aprendizagem Baseada em Problemas: Características, Processos e Racionalidade". In: MAMEDE, Silvia \& PENAFORTE, Josias Cavalcanti (orgs.). Aprendizagem Baseada em Problemas: Anatomia de uma Nova Abordagem Educacional. Fortaleza: Hucitec, 2001, pp. 25-48.

PELIZZARI, Adriana; KRIEGL, Maria de Lurdes; BARON, Márcia Pirih; FINGK, Nelcy Teresina Lubi \& DOROCINSKI, Solange Inês. "Teoria da Aprendizagem Significativa segundo Ausubel". Revista PEC, Curitiba, vol. 2, n. 1, pp. 37-42, jul. 2001-jul. 2002.
RIBEIRO, Luis Roberto de Camargo. Aprendizado Baseado em Problemas. São Carlos: UFSCAR; Fundação de Apoio Institucional, 2008.

VARGAS, Julio Vásquez; CABRERA, Moisés Barrantes \& VEGA, Virgilio Rosell. Metodología de Aprendizaje Basado en Solución de Problemas - PBLM. Trujillo: Editorial UNI, 1996 (Innovaciones en Educación Médica, 4).

ZITSCHER, Harriet Christiane. Metodologia do Ensino Jurídico com Casos: Teoria \& Prática. Belo Horizonte: Del Rey, 1999.

Publicado em 04/07/2018. 